Revista Aspas

ppgac - USP

Artigo

\title{
QUANDO A ESTÉTICA REALISTA SE TORNA SIMBÓLICA: O JARDIM DE CEREJEIRAS DE PETER BROOK (1981)
}

\author{
WHEN REALISTIC AESTHETICS BECOME SYMBOLIC: PETER \\ BROOK'S CHERRY ORCHARD (1981)
}

CUANDO LA ESTÉTICA REALISTA SE VUELVE SIMBÓLICA: EL JARDÍN DE LOS CEREZOS DE PETER BROOK (1981)

\section{Sergio Ricardo Lessa Ortiz}

Sergio Ricardo Lessa Ortiz Universidade de São Paulo / Centro Universitário Belas Artes de São Paulo; Doutor; Pesquisa concluída em 2020. Cenografia e

Traje de cena. Fausto Roberto Poço Viana. Professor de Arquitetura e Urbanismo e Artes Cênicas, Coordenador da PósGraduação em Cenografia e Figurino no Centro Universitário Belas Artes de São Paulo. E-mail: sergio.ortiz@belasartes.br. 


\section{Resumo}

Este artigo aborda questões sobre o processo concepção dos elementos visuais do espetáculo $O$ Jardim das Cerejeiras de Peter Brook. Por meio de leitura de textos e análise de registros do espetáculo busca-se apontar o impacto da cenografia simbólica nos cenários do espetáculo e nos trajes de cena elaborados por Chloé Obolensky, cenógrafa que estreou com essa montagem no Centro Internacional de Pesquisa Teatral (CICT) em 1981. Como referencial teórico para embasamento do artigo, serão utilizados Larissa Elias com 0 texto Está à venda $O$ Jardim das Cerejeiras: Peter Brook via Anton Tchekhov, Christine Hamon, Beatrice Piccon-Vallin e Mirela Nedelco-Patureau em La Cerisaie et la vitalité tchekhovienne, além de $\mathrm{O}$ ponto de Mudança de Peter Brook.

Palavras-chave: Cenografia, Traje de cena, Tchekhov, Peter Brook, Cenografia simbólica

\section{Abstract}

This article addresses questions about the process of designing the visual elements of Peter Brook's play Cherry Orchard. Through the reading of texts and analysis of the play, the aim is to point out the impact of symbolic scenography in the set design and the costumes design created by Chloé Obolensky, set designer who debuted with this montage at the International Center for Theatrical Research (CICT) in 1981. As a theoretical framework for the article, Larissa Elias will be used with the text Está à venda O Jardim das Cerejeiras: Peter Brook via Anton Tchekhov, Christine Hamon, Beatrice Piccon-Vallin and Mirela Nedelco-Patureau in La Cerisaie et la vitalité tchekhovienne, and Peter Brook's Shifting Point. Keywords: Set design, Costume design, Chekhov, Peter Brook, Symbolic scenography

\section{Resumen}

Este artículo aborda cuestiones sobre el proceso de diseño de los elementos visuales del espectáculo El Jardín de los Cerezos de Peter Brook. A través de la lectura de textos y el análisis de los registros del espectáculo, se pretende señalar el impacto de la escenografía simbólica en los escenarios del espectáculo en el vestuario escénico creado por Chloé Obolensky, escenógrafa que debutó con este montaje en el Centro Internacional de Investigaciones Teatrales (CICT) en 1981. Como marco teórico para el artículo, Larissa Elias se utilizará con el texto Está à venda O Jardim das Cerejeiras: Peter Brook via Anton Tchekhov, Christine 
Hamon, Beatrice Piccon-Vallin y Mirela Nedelco-Patureau en La Cerisaie et la vitalité tchekhovienne, más allá de Shifting Point de Peter Brook.

Palabras clave: Escenografía, Traje de escena, Chéjov, Peter Brook, Escenografia simbólica

\section{Introdução}

Embora Peter Stephen Paul Brook tenha nascido em Londres, seus antepassados são russos. Em entrevista a Collete Godard (1981), o diretor inglês relatou que já havia lido as quatro ou cinco versões do texto de Tchekhov - $O$ Jardim das Cerejeiras - que existiam em francês na época e as várias em inglês, além do texto original em russo quando decidiu montar o espetáculo.

\section{A encenação de O Jardim das Cerejeiras (1981)}

No processo de $O$ Jardim das Cerejeiras, uma das principais preocupações da direção foi a fidelidade ao texto de Tchekhov e, consequentemente, estar atento à precisão, uma vez que essa era uma das qualidades essenciais do autor. Decidiram que o texto adaptado ao francês fosse exatamente tão forte e realista quanto o original. Uma questão que vale ser ressaltada na encenação de Brook foi o ritmo proposto, que se contrapunha ao criticado "ritmo ralentado" (ELIAS, 2015, p. 177) da montagem de Stanislávski no Teatro de Arte de Moscou, revelado por Meyerhold em carta a Tchekhov.

Brook definiu a divisão do espetáculo por quadros e não por atos, conforme o texto de Tchekhov. Vale ressaltar que o entendimento de ritmo é uma questão relevante para compreender essa concepção de Brook. Além da aceleração das falas, o ritmo da organização do espaço e a cadência da movimentação espacial são fundamentais para a determinação do aspecto mais próximo da comicidade pretendida no espetáculo. É importante destacar também que, quando Brook decidiu montar o espetáculo na primavera de 1981, o Centre International de Créations Théâtrales (CICT) havia renovado 
completamente o seu quadro de atores, permanecendo entre eles somente sua esposa, Natasha Parry, que interpretou Liubov.

Foi o momento em que se estabeleceu o princípio de que qualquer intérprete poderia encenar qualquer personagem, rompendo com os padrões de que seria importante para o sucesso do espetáculo que houvesse uma concordância entre a aparência física da personagem com o tipo físico do ator. Conferindo, portanto, uma liberdade para que o artista pudesse ressaltar as suas qualidades, independente de etnia e idade. Hunt e Reeves (1995), no texto Director in perspective, indicam que houve um processo um pouco conturbado no início da montagem: alguns atores se recusaram a interpretar alguns papéis, ao considerar que o papel era pequeno demais.

Dois dos atores que participaram dessa montagem foram: Michel Piccoli, que realizou Gaev, e o experiente cômico Robert Muzeau que interpretou Firs. Muzeau, que já estava aposentado, disse que esperou por quase sessenta anos para fazer Tchekhov, aceitando o papel com bastante satisfação e muita gratidão. Deve ser destacado, também, que foi neste espetáculo que tivemos a presença de uma nova colaboradora, responsável pelos cenários e figurinos da peça, a designer Chloé Obolensky, que foi contatada para fazer parte da equipe, pois havia acabado de publicar o livro O Império Russo: um retrato em fotografias (1979) que reunia fotografias antigas da família de seu marido.

Naquele momento Brook imediatamente percebeu que a designer seria ideal para evocar o universo russo do início do século XX pretendido para o espetáculo $O$ Jardim das Cerejeiras no Théâtre des Bouffes du Nord. De acordo com Hunt e Reeves (1995), os ensaios do espetáculo duraram dez semanas, aproximadamente dois meses. E, no primeiro dia, Brook ofereceu para a equipe um luxuoso jantar russo para que os artistas pudessem se ambientar ao clima proposto.

Deve-se destacar que, na montagem, houve um intenso respeito às rubricas propostas por Tchekhov e, mesmo com a adaptação do texto, havia uma grande fidelidade à versão do autor. Segundo Georges Banu (2001), Brook indicou que haveria um grande problema de atuação se a peça não tivesse uma expressiva vitalidade e rompesse com a visão de um texto 
languido e melancólico, usualmente utilizada nas encenações das peças do autor russo.

Nessas personagens há um evidente desejo de se mostrarem vivas, o que afastou a ideia de que o desgaste da classe social corresponderia, neste caso, ao desgaste do ser humano. Assim, a atuação teve uma uniformidade e uma sintonia significativas, que tornava perceptível ao público a interação entre os atores, mesmo em cenas em que eles só passavam uns pelos outros.

Sobre o processo de construção cênica, durante os ensaios, os atores começaram a utilizar todos os espaços do teatro: balcões, janelas e escadas. Logo, todo o teatro se tornou vivo para o grupo, como relatou Natasha Parry (apud TODD; LECAT, 2003), que encenou Liubov Ranievskaia. Esse depoimento da atriz, expresso no livro The Open Circle (TODD; LECAT, 2003), revelou que a familiaridade com o espaço auxiliou sobremaneira a comunicação estabelecida em cena, o que contribuiu, definitivamente, para que o Théâtre des Bouffes du Nord se tornasse também importante na montagem.

A montagem de Brook se passa em um só lugar: o teatro. Fato este que permitiu estabelecer, ao espetáculo, uma relação de interposição entre a vida e o teatro, uma vez que optou por tornar o espaço do teatro na amada e degradada propriedade de Ranievskaia. Nestes termos, evidencia-se a metalinguagem estabelecida pela encenação, uma vez que o espaço de ensaio - o Théâtre des Bouffes du Nord -, era o local da propriedade do jardim das cerejeiras - casa das personagens tchekhovianos; e ambos eram espaços em ruínas, tanto a casa degradada e sagrada da família de Liubov quanto a sede dos atores.

De modo a reforçar a posição de destaque do espaço teatral na peça, as rampas, as escadas laterais, as paredes manchadas, as portas, os corredores entre as arquibancadas, a galeria circular por trás delas, os balcões nos andares superiores, ou seja, todos elementos da arquitetura do próprio teatro foram incorporados à montagem. $\mathrm{O}$ aspecto degradado das paredes descascadas que Brook encontrou quando decidiu se estabelecer neste local, se encaixou perfeitamente com as ruínas ambientadas na casa 
deteriorada do texto de Tchekhov, o que estimulava a imaginação do espectador a se colocar naquela situação.

Percebe-se que o espetáculo realizado por Brook caminhou no sentido de caracterizar seu teatro com um processo de eliminar de cena tudo o que era supérfluo, em busca de uma simplicidade associada à profundidade da representação. Hamon, Picon-Vallin e Nedelco-Patureau (2008), em seu texto La Cerisaie et la vitalité tchekhovienne, ressaltam que, é possível identificar traços das lições espirituais na encenação que procura seguir com um fluxo livre e contínuo de energia em cena, ao se estabelecer um constante intercâmbio de energias entre atores e espectadores proporcionando uma corrente de troca contínua. O público se integra à encenação e participa do trabalho proposto pelo estímulo à sua imaginação, permitindo com que faça parte do processo de construção cênica.

O espaço interior da casa da peça é refinado, como também é o espaço vazio do teatro. Não existem móveis, cortinas ou quaisquer outros elementos. Segundo Hamon, Picon-Vallin e Nedelco-Patureau (1985), o espaço é justamente apresentado vazio como forma de reforçar a intensa história de desapego que é retratada em $O$ Jardim das Cerejeiras, escrita por Theckhov quase à beira da morte. Nesse jogo cênico Brook estabeleceu que o pomar com o esplêndido jardim das cerejeiras fosse construído na imagem mental do espectador, ao longo da encenação. Para os autores supracitados, essa construção imagética constrói uma relação dupla: representa tanto a imagem de um símbolo de felicidade, como também uma projeção visual do silêncio, ao qual certas antigas meditações orientais conduzem ao final do seu estágio de observação.

Durante a encenação havia uma constante: eram criadas relações entre espectadores e atores para que se tornassem íntimos uns dos outros. Por meio dos jogos de improvisações, realizados no período de ensaios, a encenação conseguiu envolver a plateia para que se tornasse parceira das personagens em diferentes situações, tais como a evocação ao lendário Jardim das Cerejeiras e a colocação do tapete que delimitada o ambiente da residência chegando até os pés do público. O contraste estabelecido entre a comicidade de algumas circunstâncias e a densidade de uma realidade 
obscura da existência humana, permitiu que os espectadores não assistissem ao espetáculo em uma posição de julgamento sobre os atos contestáveis das personagens. Estavam simplesmente refletindo sobre uma história que trazia a ponderação sobre a questão da impermanência da existência humana no mundo.

\section{O espaço de representação e os trajes de cena de $O$ Jardim das Cerejeiras}

A encenação ocorre em todo o teatro, porém predominam as cenas no espaço central de representação do Théâtre des Bouffes du Nord. A maior exceção é o quarto ato, quando se descentraliza e o espaço se abre tanto na vertical quanto na horizontal, ocupando as laterais, o alto e o fundo do palco e a frente do teatro. É importante evidenciar que um elemento presente nas pesquisas de Brook, desde as suas investidas nas viagens à África que contribuíram para o protagonismo do espaço nesta encenação, é o tapete em cena - ou seja, os espetáculos do carpet show'.

Os tapetes utilizados em $O$ Jardim das Cerejeiras adquirem novas proporções, uma vez que não foram colocados para delimitar a área de representação. Brook solicitou que o espaço de representação fosse despojado de cenários, exceto pelos tapetes persas gastos que eram lançados pelo chão. Sendo assim seriam os únicos resquícios de que a casa de Ranievskaia havia sido uma casa aconchegante e reconfortante, apesar da sua degradação.

No espaço cênico desta obra, os tapetes tocavam as paredes laterais do teatro e percorriam quase todo o espaço. Essa foi uma das formas que a cenógrafa encontrou para associar o teatro à imagem da casa. Como os tapetes floridos tocavam tanto as paredes do teatro como os pés do público, eles deixaram de ter a função de restringir o espaço de atuação e se tornaram responsáveis por reforçar a imersão dos espectadores na velha propriedade

\footnotetext{
${ }^{1}$ Carpet show (Espetáculo no tapete) são eventos em que o tapete servia como demarcação da área de representação para os atores.
} 
da família. Fato este que foi reforçado com as personagens falando do balcão, movimentando-se constantemente por todo o teatro e por entre o público.

Outro aspecto fundamental no processo artístico de Brook é o estímulo à imaginação do público. Uma das maneiras mais eficientes encontradas neste espetáculo é a indicação da imagem do jardim, como se estivesse atrás do público. Os atores se referem a ele como se estivesse atrás da plateia, o que força que cada um estabeleça em seu imaginário o que seria o jardim. Os poucos móveis, os biombos, que fazem as divisórias dos ambientes da residência, o armário centenário, os tecidos desbotados, as paredes descascadas denotam uma casa quase vazia, antiga e decadente.

Durante o primeiro ato da peça, os biombos e os tapetes floridos com poucos móveis compõem o ambiente de representação. Os atores estão, na maior parte do tempo, mais próximos do nível do chão - sentados diretamente nele ou sentados nas poltronas, em seus braços, ou em cadeiras. Deve-se atentar que para Tchekhov a ação transcorre no quarto de criança, ou seja, um lugar da infância, das brincadeiras, das memórias, do passado com o qual os personagens se reencontram. Na encenação, boa parte da associação com o universo infantil é realizada pela movimentação dos atores nesse plano baixo e mais horizontalizado.

No segundo ato a ação se passa em um local externo à residência, entre a casa e o jardim. A solução adotada pela encenação é concentrar a área de representação na parte central, criando um retângulo sem qualquer elemento além dos tapetes. Este é o momento em que os atores exercitam a imaginação do público, pois o jardim é recorrentemente indicado nas áreas do entorno, nas costas do público, por meio da indicação de foco visual dos atores em cena.

No terceiro ato a ação é novamente concentrada no retângulo inicial, porém, de modo distinto dos demais atos, em que se vê todo o espaço cênico. Até este ato, não havia quaisquer móveis, cadeiras ou sofás para que as personagens se sentassem, exceto um tapete enrolado que compunha estranhamente a cena no primeiro ato. Neste momento, sua configuração é intencionalmente fragmentada, pois alguns biombos são posicionados para seccionar o retângulo da representação, formando, assim, alguns corredores. 
No entanto, não se separam os espaços de representação completamente, permite-se que se veja a ação da festa que ocorre ao fundo, caracterizada pela movimentação dos atores.

Vale destacar que é durante esse ato que Lopakhin anuncia a compra do jardim das cerejeiras. $O$ ator se movimenta irregularmente pela área de representação, andando da frente ao fundo do espaço por diversas vezes. Até o momento em que bate com os braços no biombo do fundo que delimita o espaço de representação. $O$ tapete que cobre o biombo balança e cai de costas sobre outro deles, derrubando-os. Ouve-se um barulho de grandes proporções que evidencia um dos momentos mais impactantes da montagem, pois o efeito criado com o desabamento dos biombos, simbolicamente prenuncia o que irá acontecer à propriedade.

No quarto e último ato, o espaço se abre completamente. Os tapetes são removidos, restando apenas um deles no chão, em segundo plano. Sobre ele percebe-se um amontoado dos outros tapetes enrolados, um pano e mais alguns objetos. Há malas espalhadas pelo espaço e, sobre uma delas, encontra-se uma bandeja com taças de champanhe. Ao fundo se vê um lençol pendurado e a poltrona sem banqueta está coberta por um tecido claro. A ação cênica é estendida para fora da área central de representação, utilizando-se bastante as rampas, as laterais frontais, um dos balcões superiores do teatro, as escadarias e um curioso buraco na parede de contorno irregular, que se assemelha a uma porta inacabada.

A imagem da ruína da casa e da iminente destruição do jardim está estampada definitivamente nas paredes e no chão do teatro, agora totalmente desnudos, despojados de quase todos os móveis e adereços. Resta apenas a poltrona, espécie de leito de morte, em que Firs, que fica "esquecido" na casa deixada para trás, se deita e dorme. É importante destacar a forma como Brook e os seus atores conceberam intencionalmente a movimentação das personagens em cena.

Para Hamon, Picon-Vallin e Nedelco-Patureau (1985) o espaço cênico proposto era a personalização da residência decadente de Liubov. Sua estrutura, em todos os atos, parte de um evidente espaço vazio que era envolvido pelas paredes destruídas, ora remetendo a uma cor acinzentada da 
fuligem da destruição do bombardeiro, ora parecendo avermelhadas com vestígios de pinturas antigas do espaço cênico anterior a ocupação do grupo. O piso se assemelhava a uma colcha de retalhos de tapetes orientais de diversos tamanhos, que se sobrepunham. Devido ao seu evidente desgaste, ressaltavam a degradação daquele ambiente.

Vale relembrar que os tapetes traziam também a memória do passado da montagem anterior de Brook. Além do resgate da memória dos próprios atores do grupo, é preciso considerar que a maciez do piso e a decoração com desenhos coloridos da cultura persa, para os autores supramencionados, evocavam um estágio de relaxamento que trazia a simbologia de um estilo de vida europeu da época, inspirados na cultura oriental. Além disso, compunham traços do espaço da infância, dos segredos e dos jogos infantis propostos pelo texto. Remetiam, ainda, a um passado antigo em que havia abundância de recursos financeiros, um passado mais distante das personagens, que resgatam memórias de quando eram crianças para se sentirem mais confortáveis com seu atual estado.

Para os trajes de cena, que definitivamente contribuem para a construção visual do espetáculo e consequentemente para o espaço de representação, observa-se a escolha de uma composição fortemente vinculada ao momento histórico em que o texto foi escrito. Ou seja, os trajes se aproximam de confecções do final do século XIX e início do século XX. Esta composição tem um forte embasamento histórico e foram desenhados por Obolensky com base no livro que havia escrito.

A elegância e o corte das roupas se opõem à condição degradada do espaço cênico. A cenografia, composta pelos tapetes floridos e pelas paredes desbotadas, contrasta fortemente com as roupas lisas que combinam o claro e o escuro, com a prevalência do escuro. Há a predominância dos tons escuros, principalmente os pretos (no primeiro e terceiro atos), nos elegantes sobretudos, paletós, calças e saias, com alguns detalhes claros nos demais componentes do figurino. No segundo ato, determina-se um contraponto em relação aos demais trajes, pois sobressai uma paleta de cores calcada em tons claros, em contraste com alguns elementos em cinza e preto. 
As estações do ano e consequentemente as sensações de frio e calor, também eram transmitidas tanto pelas formas e cortes dos trajes, quanto pela paleta de cores. Os acessórios contribuíam, de maneira similar, para que fosse possível estabelecer a leitura do clima. Ranievskaia, por exemplo, no segundo ato que indica o período de verão, veste um longo vestido branco e um chapéu, que é agitado durante a encenação, indicando se tratar de um período de intenso calor.

\section{Considerações finais}

Ao relacionar os elementos presentes na concepção espacial do espetáculo $O$ Jardim das Cerejeiras com a trajetória de Brook, fica evidente a permanência de alguns elementos de investigação do grupo, mesmo que a proposta tenha sido por uma maior fidelidade ao texto e ao contexto de Tchekhov. O que, para alguns críticos, poderia parecer um ruído frente ao processo de simplificação tanto da cena, quanto dos elementos visuais do espetáculo. Deve-se, porém, atentar que esta escolha adquiriu algumas características simbólicas.

O Théâtre des Bouffes du Nord intencionalmente revestido por tapetes floridos, além de incluir o espectador diretamente na cena de forma a participar ativamente do espetáculo, faz com que o espaço se torne também um dos protagonistas na ação. Ainda que se explore uma forma distinta da usual nos processos de Brook para o estabelecimento do jogo teatral, aproximando $\mathrm{o}$ ato cênico do espectador, é evidente a exploração da imaginação da plateia também nessa montagem. O exercício da imaginação é substancialmente indicado pela sugestão que os atores fazem do jardim das cerejeiras que, em momento algum, é representado em cena.

Outro elemento de permanência na pesquisa teatral de Brook é a concepção do espaço vazio. Mesmo que o Théâtre des Bouffes du Nord tenha se tornado parte da encenação, a determinação de poucos elementos cenográficos no espaço interior da casa reforça o conceito primordial na concepção cênica brookiana que utiliza a imaginação do espectador como parte ativa da encenação. Nessa condição há uma evidente alteração da 
proposição espacial do espetáculo, o qual, definitivamente, se estabelece como um espaço simbolista, uma vez que o teatro, por meio da metalinguagem proposta, se torna, em sua totalidade, a casa abandonada dos aristocratas.

Contudo, ao compreender que os trajes de cena influenciam diretamente na composição espacial, observa-se que existe uma reprodução realista do período em que se estabelece a ação cênica proposta por Tchekhov. Uma vez que há indícios e relatos do próprio encenador evidenciase que a escolha da nova cenógrafa e figurinista do grupo foi embasada na publicação do seu livro sobre registros fotográficos históricos. Compreendese que houve uma evolução no sentido de uma proposta que primava pela simplificação cênica, mas que não se completa em todos os elementos visuais do espetáculo.

\section{Referências}

BANU, Georges (Org.) Brook. Les voies de la création théâtrale. v.13. Paris: CNRS, 2002. (Col. Arts du spectacle).

BROOK, Peter. Fios do tempo: memórias. Rio de Janeiro: Bertrand Brasil, 2000. . O ponto de mudança: quarenta anos de experiências teatrais: 1946-1987. Rio de Janeiro: Civilização Brasileira, 1994. ELIAS, Larissa. Está à venda O Jardim das Cerejeiras: Peter Brook via Anton Tchekhov. Rio de Janeiro: 7Letras, 2015.

GODARD, Colette. In: PETER BROOK SITE OFFICIEL-NEWS. Disponível em:<http://www.newspeterbrook.com/1981/03/05/la-cerisaie-1981/>. Acesso em 11 dezembro 2020.

HAMON, Christine; PICON-VALLIN, Beatrice; NEDELCO-PATUREAU, Mirela. La Cerisaie et la vitalité tchekhovienne. In: BANU, Georges (ed.). Les voies de la création théatrale - tome 13: Brook: études, textes, propos. Paris: Éditions du Centre National de la Recherche Scientifique, 1985. p. 256-307.

TODD, Andrew \& LECAT, Jean-Guy Peter Brook: directors in perspective. Cambridge: University Press, 1995.

TODD, Andrew \& LECAT, Jean-Guy. The open circle: Peter Brook's Theatre Environments. New York: Faber and Faber Inc., 2003. 